\title{
Mitral degenerative disease mimicking a valvular tumor: a case report
}

\author{
Eiki Tayama*, Tomohiro Ueda, Ryusuke Mori, Ken-ichi Imasaka and Yukihiro Tomita
}

\begin{abstract}
Background: In rare cases, echo findings of degenerative valve disease is similar to valvular mass.

Case Presentation: A 56-year-old woman was evaluated for palpitation. Echocardiography revealed an 8- mm mass on the anterior mitral leaflet with minimal mitral insufficiency. Resection of the valve tumor was attempted to prevent a possible embolism. However, the lesion was not a tumor, but an aneurysm-like bulge on the anterior leaflet without chorda elongation. Triangular resection and ring annuloplasty were performed. The patient's postoperative course was uneventful. Pathological examination revealeddegenerative disease.

Conclusions: This case illustrates that a valvular mass that looks like a tumor by echocardiography may actually be degenerative regardless of the presence of mitral insufficiency.
\end{abstract}

Keywords: Mitral valve, Valvular tumor, Valvular mass, Degenerative disease, Echocardiography

\section{Background}

When a mass is observed on the mitral valve by echocardiography, infectious vegetation and various types of valve tumors are generally suspected [1-6]. However, degenerative disease also occasionally looks like a valvular mass [6]. Diagnosis of degenerative disease is not usually difficult because it is characterized by flail leaflet motion with concomitant regurgitation. If the diseased lesion is limited in size and regurgitation is not significant, however, diagnosis becomes more difficult. We herein report a case of mitral degenerative disease without regurgitation that looked like a valvular tumor.

\section{Case presentation}

A 56-year-old woman with no infectious history was evaluated for palpitation. She had regular pulse rhythm and no heart murmur. Electrocardiography, Holter, electrocardiography, and chest $\mathrm{X}$-ray findings were normal. Transthoracic echocardiography revealed an $8-\times 8$-mm mass on the posterior side of the anterior mitral leaflet with minimal mitral insufficiency (Fig. 1). The left ventricular motion and dimensions were normal. Transesophageal echocardiography demonstrated similar findings. Computed tomography showed no systemic embolism. Because

\footnotetext{
* Correspondence: e.tayama@kyumed.jp

Department of Cardiovascular Surgery, Clinical Research Institute, Kyushu Medical Center, National Hospital Organization, Fukuoka, Japan
}

a valve tumor was suspected, surgical resection was attempted to prevent a possible systemic embolism. During surgery, we found that the lesion was not a tumor, but an aneurysm-like bulge on the anterior leaflet without chorda elongation (Fig. 2). Triangular resection and ring annuloplasty were performed, and the patient's postoperative course was uneventful. Pathological examination showed myxomatous change, fibrosis, and hyalinization, confirming a diagnosis of degenerative disease. Now, her condition has been good without any mitral valve abnormality including regurgitation at postoperative 10 months.

\section{Discussion}

When a mass is found on the mitral valve by echocardiography, an infectious vegetation is usually suspected first. Various types of valve tumors may be suspected less frequently. Primary cardiac tumors are uncommon, accounting for $0.021 \%$ among 1 million autopsies [1]. Primary "valve" tumors are rarer, constituting less than $10 \%$ of all primary cardiac tumors [2,3]. Despite their low incidence, valve tumors are clinically very important because they occasionally become symptomatic, causing serious neurological symptoms or sudden death; this is more common with mitral than aortic valve tumors [4]. The most common histological type of valve tumor is papillary fibroelastoma, followed by myxoma, fibroma, sarcoma, and others [4]. If a valve mass is a highly mobile 


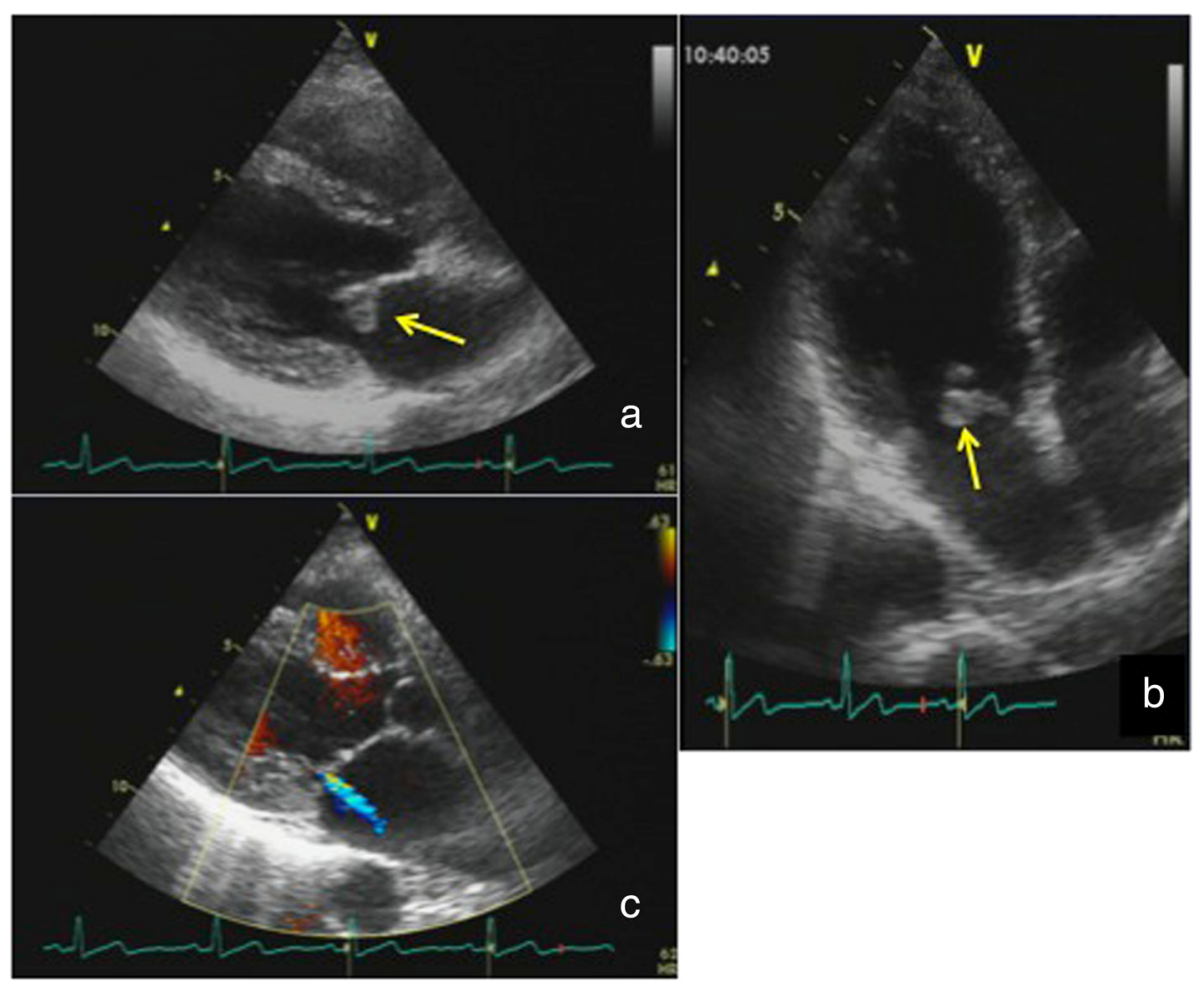

Fig 1 Echocardiographic findings. An 8- $\times 8$-mm tumor-like lesion $(\uparrow)$ was present on the posterior side of the anterior mitral leaflet with trivial regurgitation. a, c Long-axis view. b Four-chamber view

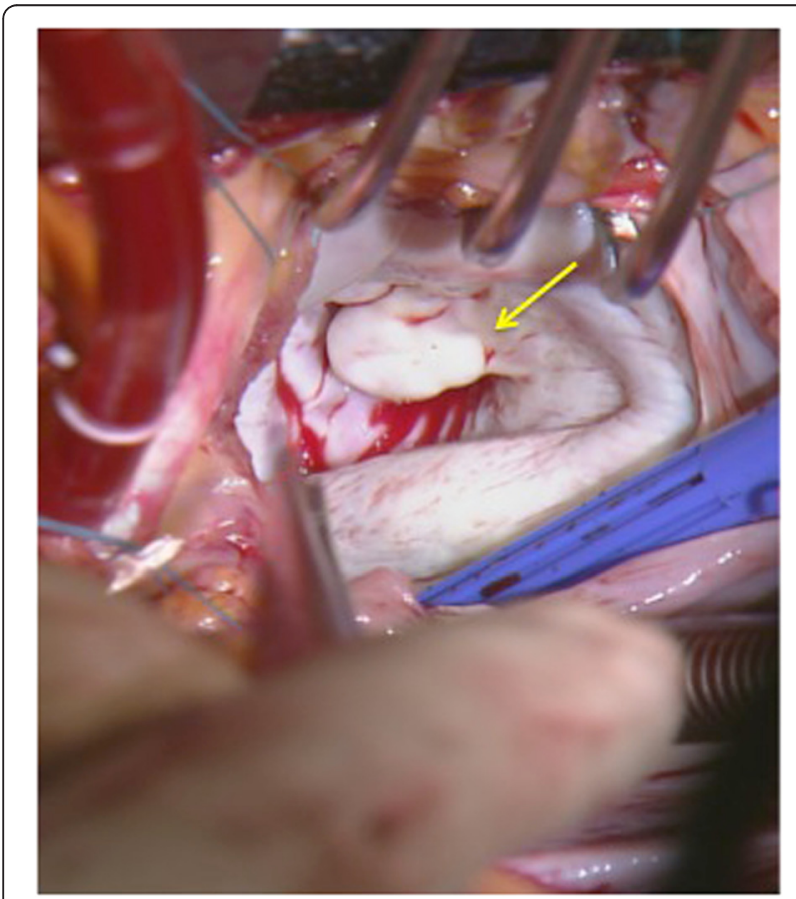

Fig 2 Intraoperative findings (operator's view). An aneurysm-like bulge was found on the posterior side of the anterior mitral leaflet and large, surgical resection is recommended regardless of the histological findings or presence of symptoms [4-7].

In contrast, degenerative mitral valve disease, such that caused by fibroelastic deficiency, is a common disorder affecting approximately $2 \%$ of the population [8]. Degenerative valve disease occasionally looks like a valve mass [6]. In patients with degenerative valve disease, fibrin deficiency often leads to rupture of one or more thinned and elongated chordae, those often associated with the middle scallop of the posterior leaflet. As a result, most patients with degenerative mitral valve disease develop leaflet prolapse, resulting in varying degrees of regurgitation due to leaflet malcoaptation during ventricular contraction. However, if chordal damage is minimal despite the presence of myxomatous change in the leaflet, valve regurgitation can be minimal. In such cases, distinction between a tumor and degenerative disease is difficult [6].

\section{Conclusion}

In conclusion, an aneurysm-like bulge on the leaflet without major regurgitation was misdiagnosed as a valve tumor in this case; the patient actually had degenerative disease. Our assumption that degenerative disease should coexist with regurgitation led to misdiagnosis. Our experience serves to remind clinicians that when a valvular mass 
looks like a tumor by echocardiography, it may instead be a degenerative change, even without mitral insufficiency.

\section{Consent}

Written informed consent was obtained from the patient for publication of this Case Report and any accompanying images. A copy of the written consent is available for review by the Editor-in-Chief of this journal. The ethics committee of our institution approved to publish this case report.

\section{Competing interests}

The authors declare that they have no competing interests.

\section{Authors' contributions}

ET wrote the manuscript. UT and RM obtained the data and written consent. $\mathrm{KI}$ and $\mathrm{YT}$ performed the literature review and participated in the writing of the manuscript. All authors read and approved the final manuscript.

Received: 25 August 2015 Accepted: 27 October 2015

Published online: 02 November 2015

\section{References}

1. Reynen K. Frequency of primary tumors of the heart. Am J Cardiolo. 1996;77:107.

2. Chitwood WR. Cardiac neoplasms: current diagnosis, pathology, and therapy. J Cardiac Surg. 1988;3:119-54.

3. McFadden PM, Lacy JR. Intracardiac papillary fibroelastoma: an occult cause of embolic neurologic deficit. Ann Thorac Surg. 1987;43:667-9.

4. Edwards FH, Hale D, Cohen A, Thompson L, Pezzella AT, Virmani R. Primary cardiac valve tumors. Ann Thorac Surg. 1991;52:1127-31.

5. Gowda RM, Khan IA, Nair CK, Mehta NJ, Vasavada BC, Sacchi TJ. Cardiac papillary fibroelastoma: a comprehensive analysis of 725 cases. Am Heart J. 2003;146:404-10.

6. Sun JP, Asher CR, Yang XS, Cheng GG, Scalia GM, Msssed AG, et al. Clinical and echocardiographic characteristics of papillary fibroelastoma: a retrospective and prospective surgery in 162 patients. Circulation. 2001;103:2687-93.

7. Ngaage DL, Mullany CJ, Daly RC, Dearani JA, Edwards WD, Tazelaar HD, et al. Surgical treatment of cardiac papillary fibroelastoma: a single center experience with eighty-eight patients. Ann Thorac Surg. 2005;80:1712-8.

8. Enriquez-Sarano M, Akins CW, Vahanian A. Mitral regurgitation. Lancet. 2009;373:1382-94.

\section{Submit your next manuscript to BioMed Central and take full advantage of:}

- Convenient online submission

- Thorough peer review

- No space constraints or color figure charges

- Immediate publication on acceptance

- Inclusion in PubMed, CAS, Scopus and Google Scholar

- Research which is freely available for redistribution 